\title{
Light dominates the diurnal emissions of herbivore-induced volatiles in wild tobacco
}

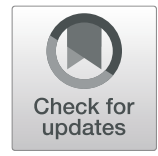

Jun He $\mathrm{H}^{1,2^{*}}$, Rayko Halitschke ${ }^{2}$, Meredith C. Schuman ${ }^{2,3}$ and lan T. Baldwin ${ }^{2^{*}}$

\begin{abstract}
Background: Timing is everything when it comes to the fitness outcome of a plant's ecological interactions, and accurate timing is particularly relevant for interactions with herbivores or mutualists that are based on ephemeral emissions of volatile organic compounds. Previous studies of the wild tobacco N. attenuata have found associations between the diurnal timing of volatile emissions, and daytime predation of herbivores by their natural enemies.

Results: Here, we investigated the role of light in regulating two biosynthetic groups of volatiles, terpenoids and green leaf volatiles (GLVs), which dominate the herbivore-induced bouquet of $\mathrm{N}$. attenuata. Light deprivation strongly suppressed terpenoid emissions while enhancing GLV emissions, albeit with a time lag. Silencing the expression of photoreceptor genes did not alter terpenoid emission rhythms, but silencing expression of the phytochrome gene, NaPhyB1, disordered the emission of the GLV (Z)-3-hexenyl acetate. External abscisic acid (ABA) treatments increased stomatal resistance, but did not truncate the emission of terpenoid volatiles (recovered in the headspace). However, ABA treatment enhanced GLV emissions and leaf internal pools (recovered from tissue), and reduced internal linalool pools. In contrast to the pattern of diurnal terpenoid emissions and nocturnal GLV emissions, transcripts of herbivore-induced plant volatile (HIPV) biosynthetic genes peaked during the day. The promotor regions of these genes were populated with various cis-acting regulatory elements involved in light-, stress-, phytohormone- and circadian regulation.

Conclusions: This research provides insights into the complexity of the mechanisms involved in the regulation of HIPV bouquets, a mechanistic complexity which rivals the functional complexity of HIPVs, which includes repelling herbivores, calling for body guards, and attracting pollinators.
\end{abstract}

Keywords: Plant diurnal rhythms, Herbivory, Light regulation, Terpenoid volatiles, GLVs, HIPVs

\section{Background}

Living on a planet that rotates on its axis every $24 \mathrm{~h}$, most organisms' physiologies harbor rhythms that are tuned to periodic day/night cycles. For example, the plant circadian clock prepares the photosynthetic machinery for light harvesting just before sunrise and closes stomata to maintain water at noon [1]. Plant rhythms

\footnotetext{
*Correspondence: hejunyer@outlook.com; baldwin@ice.mpg.de

${ }^{1}$ National Citrus Engineering Research Center, Citrus Research Institute,

Southwest University, Xiema Street, Beibei, Chongqing 400712, People's Republic of China

${ }^{2}$ Department of Molecular Ecology, Max Planck Institute for Chemical Ecology, Hans-Knöll-Straße 8, 07745 Jena, Germany

Full list of author information is available at the end of the article
}

are also important in coordinating interactions with other organisms. For instance, snapdragon flowers diurnally emit methyl benzoate to attract day-active pollinating bees [2] but petunia flowers nocturnally emit benzaldehyde to attract night-active hawkmoths [3]. Diurnal rhythms in jasmonate signaling of $A$. thaliana are thought to be essential for its resistance against generalist cabbage loopers, Trichoplusia ni, which also feed rhythmically [4]. Both resistance of A. thaliana and infection by Botrytis cinerea vary by time of day $[5,6]$.

Herbivore-induced plant volatiles (HIPVs) mediate tritrophic interactions between plants, herbivores and natural enemies [7-9]. Plants use HIPVs to attract

(c) The Author(s). 2021 Open Access This article is licensed under a Creative Commons Attribution 4.0 International License, which permits use, sharing, adaptation, distribution and reproduction in any medium or format, as long as you give appropriate credit to the original author(s) and the source, provide a link to the Creative Commons licence, and indicate if changes were made. The images or other third party material in this article are included in the article's Creative Commons licence, unless indicated otherwise in a credit line to the material. If material is not included in the article's Creative Commons licence and your intended use is not permitted by statutory regulation or exceeds the permitted use, you will need to obtain permission directly from the copyright holder. To view a copy of this licence, visit http://creativecommons.org/licenses/by/4.0/ The Creative Commons Public Domain Dedication waiver (http://creativecommons.org/publicdomain/zero/1.0/) applies to the data made available in this article, unless otherwise stated in a credit line to the data. 
predators of herbivores and to indirectly defend themselves from herbivory. However, herbivores can also use these volatiles to locate their host plants or avoid predation [7, 8]. HIPVs usually comprise two ubiquitous groups of metabolites: green leaf volatiles (GLVs) and terpenoids. GLVs are $\mathrm{C}_{6}$ aldehydes, alcohols and esters, which are synthesized through the lipoxygenase (LOX)/ hydroperoxide lyase (HPL) pathway in almost all plants and algae [10-14]. Terpenoids are synthesized from different numbers of $\mathrm{C}_{5}$ units and are classified into hemiterpene $\left(C_{5}\right)$, monoterpene $\left(C_{10}\right)$, sesquiterpene $\left(C_{15}\right)$ and diterpene $\left(\mathrm{C}_{20}\right)$, backbones and their derivatives [11, 15]. Terpenoid volatiles are derived from mevalonate (MVA) or the 2-C-methyl-D-erythritol 4-phosphate/ 1deoxy-D-xylulose 5-phosphate (MEP/DOXP) pathway in higher plants [16], and directly synthesized by terpene synthases [15]. Both GLVs and terpenoids play roles in tri-trophic interactions, some of which function as indirect defenses for plants $[7,8]$.

HIPVs released from foliage are known to be diurnally regulated, particularly the terpenoid constituents. For example, the abundance of volatiles emitted from Picea abies foliage after methyl jasmonate elicitation, which mimic herbivore-induced emissions, is greater during day than night [17]. Similar patterns are reported for Phaseolus vulgaris HIPVs elicited by attack from $L$. huidobrensis larvae [18]. Furthermore, in $A$. аnnua the gene QH6, which encodes (-)- $\alpha$-PINENE/(-)- $\beta$-PINENE SYNTHASE, showed diurnal patterns of transcript abundance [19]. GLV emissions were induced by herbivory both during the day and during the night from Phaseolus lunatus [20], during night from Nicotiana tabacum [21], while in P. vulgaris (kidney bean), some constituents are released during light periods while others are released during dark periods [18].

In previous research with the native diploid tobacco $N$. attenuata, we found that foliar HIPV constituents, including $(E)$ - $\alpha$-bergamotene, $(E)$ - $\beta$-ocimene and linalool, were diurnally released [22-25]. These volatiles play a central role in $N$. attenuata's herbivory, defense and pollination interactions with insects and the same compounds play different roles depending on the tissue from which they are released and their timing. For example, (E)- $\alpha$-bergamotene, produced by NaTPS38, is emitted from flowers at night and increases the probing time and thus pollination success of $M$. sexta moths visiting flowers. However, when emitted from attacked leaves during the day, it attracts natural enemies of $M$. sexta larvae [24] to mediate a potent indirect defense [26]. The emission of $(E)$ - $\beta$-ocimene, produced by NaTPS 25 , was correlated with $(E)$ - $\alpha$-bergamotene emission from diverse $N$. attenuata accessions, and the two genes are co-localized on the N. attenuata genome [27]. In contrast, a QTL for the emission of linalool, a monoterpene produced by NaLIS, was mapped to a locus different from that of $(E)$ - $\alpha$-bergamotene and $(E)$ - $\beta$-ocimene. Linalool also attracts natural enemies, and can deter oviposition of M. sexta moths in a context-dependent manner [23]. GLVs have also been found to play important roles in the defense of $N$. attenuata against herbivory in nature [26]. GLVs released in the morning elicit greater predatory activity by day-active Geocoris spp. predators than does the evening-released blend of GLVs even when both blends are experimentally applied to plants during the window of Geocoris spp. activity [28]. Furthermore, transcripts of genes involved in GLV biosynthesis, including NaHPL and NaLOX2, were regulated by the plant's circadian clock $[25,29]$.

Here we confirmed that terpenoid volatile emission is greater during light periods while emission of GLVs is greater during dark periods, by manipulating the light environment of leaves independently of day-night cycles. The emission patterns of terpenoids were not altered by silencing the expression of photoreceptor genes, the supplementation of far-red light, or by increasing stomatal resistance by external abscisic acid (ABA) application. The emission pattern of GLVs, however, was changed by silencing NaPhyB1 transcripts, and increased by exogenous ABA treatments. The genes involved in terpenoid and GLV biosynthesis all showed diurnal patterns of transcript accumulation, and the promoter regions of these genes were populated by various cis-acting regulatory elements involved in light-, stress-, phytohormoneor circadian-regulated processes.

\section{Results}

Light deprivation decreased terpenoid, but increased GLV emissions

Predation assays performed with a biparential RIL population of $N$. attenuata plants grown in a field plot in the summer of 2017 revealed that $M$. sexta eggs and larvae were predated by big-eyed bugs (Geocoris spp.) during the day time (Fig. S1), consistent with previous findings [27]. Because plant volatiles play essential roles in mediating this tri-trophic interaction $[23,26]$ and to get a better understanding of their diurnal/nocturnal regulation, we collected headspace day and night time volatiles from $N$. attenuata leaves on glasshouse-grown plants elicited by wounding plus $M$. sexta larval regurgitant $(\mathrm{W}+\mathrm{R})$ using PDMS tubing pieces (Kallenbach et al. [30], Fig. 1A, B). The assayed leaf was enclosed in a plastic cup which could be wrapped using aluminum foil to locally deprive the treated leaf of light (Fig. 1A, B). We found that the emission of most terpenoid volatiles corresponded strongly to light periods, especially linalool and $(E)$ - $\alpha$-bergamotene (Fig. 1C). The emission of these terpenoid volatiles was very low during the night period (22:00-6:00), increased in the morning (6:00-10:00), and 


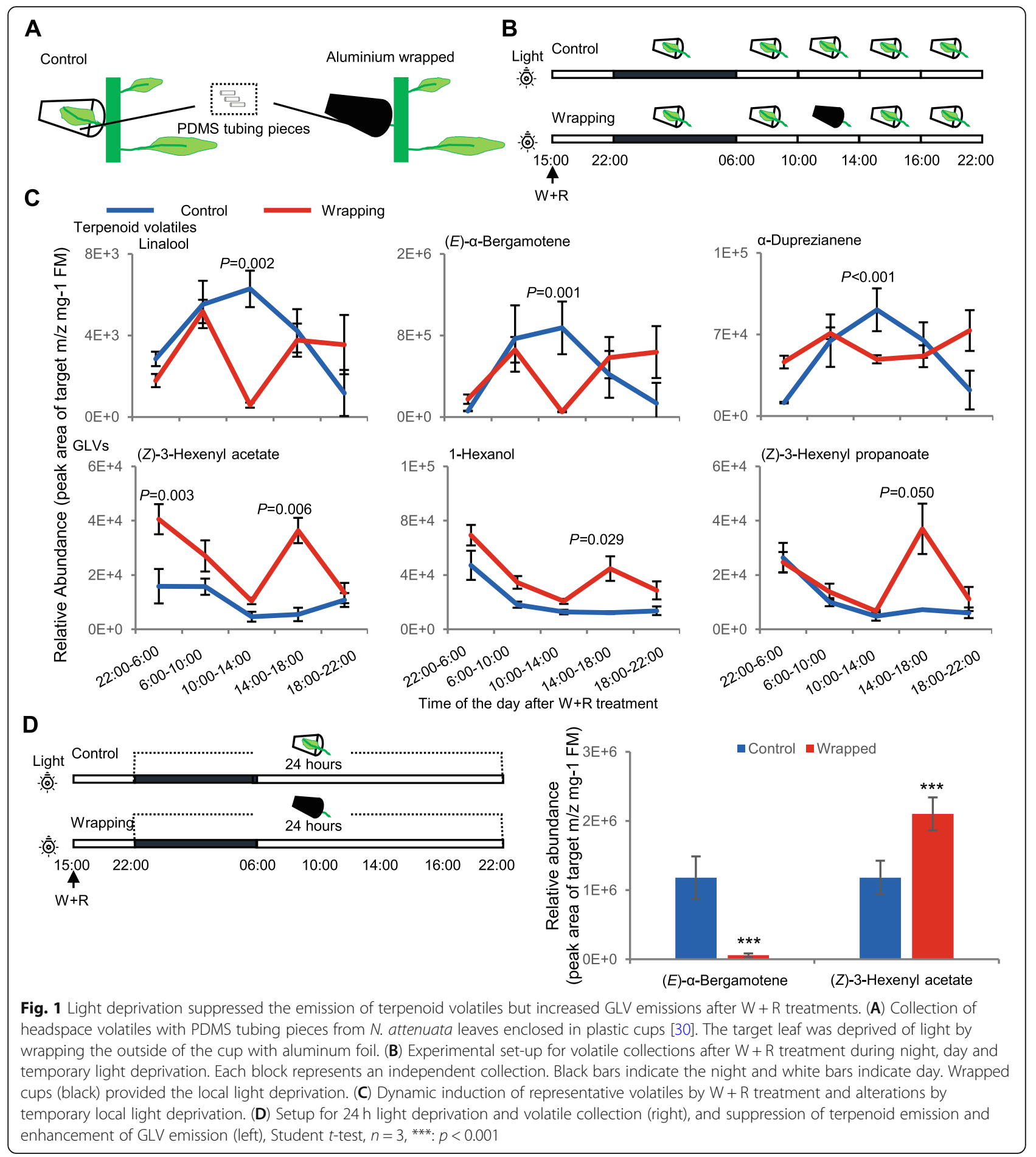

peaked during the middle of the day (10:00-14:00), then decreased in the afternoon (14:00-18:00) and returned to low levels in the evening (18:00-22:00). When the leaf was enclosed in a wrapped cup during the middle hours of the day (10:00-14:00), the emission of most terpenoids immediately decreased to low levels, comparable to those measured at night. After the foil wrapping was removed in the afternoon and evening, the emission of these terpenoid volatiles returned to control levels (Fig. $1 C)$. In contrast to the day-emitted terpenoids, many GLVs were abundantly emitted at night and steadily decreased during the day, although some, such as (Z)-3hexenyl acetate and (Z)-3-hexenyl propanoate, continued to be released at high levels in the morning. Local 
light deprivation during the middle hours of the day did not alter GLV emissions but up-regulated them in the afternoon, which likely continued through the evening hours (Fig. 1C). The decreased total terpenoid volatile emissions and increased total GLV emissions associated with light deprivation were further confirmed in single $24 \mathrm{~h}$ collections after $\mathrm{W}+\mathrm{R}$ treatments (Fig. 1D). Thus terpenoids and GLVs showed opposing responses to local light deprivation.

Because the volatile emission might also be affected by temperature and humidity caused by wrapping the cups, we monitored these two factors outside of cups, in clean cups and in wrapped cups (Fig. S2A). We found that there was only $0.8-2.4{ }^{\circ} \mathrm{C}$ drop in temperature in wrapped cups compared to clean cups during the wrapping period 10:00-14:00 (Fig. S2B). The average humidity in wrapped cups were about $9 \%$ higher than in clean cups, but it was more variable depending on the enclosed leaf (Fig. S2B). These difference in temperature and humidity were not supposed to significantly affect the volatile emission in our experimental setups because they were in the comfortable zone of the plants.

\section{Silencing NaPhyB1 expression and ABA treatments altered GLV but not terpenoid emissions}

We assessed the volatile emissions elicited by $W+R$ treatment in a series of plants individually silenced (by stable transformation with inverted repeat-ir-RNAi constructs) in the following photoreceptor genes: NaPhyB1, NaPhyB2, NaPhyB1 $x$ NaPhyB2, NaCrypt1 and NaCrypt2 (previously characterized by $\mathrm{Oh}$ et al. [31]). The emission pattern of volatiles in all the plants were largely unchanged (Fig. 2A, Fig. S3) with the exception of those of irPhyB1 plants. Particularly, in plants generated by crossing irPhyB1 with irPhyB2 to silence both phytochrome genes, (Z)-3-hexenyl acetate emissions increased in the afternoon. Supplementation of far red light did not alter total terpenoid or GLV emissions as assessed in $24 \mathrm{~h}$ collections (Fig. 2B) or collections taken every $4 \mathrm{~h}$ (Fig. S4).

\section{ABA regulated HIPVs but not via stomatal conductance}

We tested if the day/night patterns of volatile emission were controlled by changes in stomatal resistance, which might influence the release of volatiles from plant tissues (Fig. 3A, [32, 33]). We used ABA treatments to increase the stomatal resistance of leaves of empty vector control (EV) and irMPK4 plants, which, as previously described [34], have stomata that are largely in the open state and are not responsive to ABA treatments (Fig. 3A, B). ABA treatment of EV plants increased stomatal resistance during the day, but the diurnal emissions of the terpenoids, linalool and $(E)$ - $\alpha$-bergamotene, were not altered in either EV or irMPK4 plants (Fig. 3C). In contrast, emissions of (Z)-3-hexenyl acetate were upregulated at the sampling period that followed the ABA treatment and returned to control levels at the end of the day in both EV and irMPK4 plants (Fig. 3C). Interestingly, measurements of the internal leaf volatile pools revealed that ABA treatments decreased the amounts of linalool accumulated in leaves during the middle part of the day in both EV and irMPK4 plants, although it did not decrease amounts released to the headspace (Fig. 3C, D). Internal $(E)$ - $\alpha$-bergamotene pools tended to increase but were not significantly changed by ABA treatment, consistent with the headspace emissions. Internal ( $Z$ )-3-hexenyl acetate pools tracked headspace emissions, and both were enhanced by ABA treatments in EV plants, with smaller enhancements in irMPK4 plants (Fig. 3D).

Thus ABA treatment enhanced the emission of a GLV, which is more abundantly emitted in the dark, despite reducing stomatal conductance. Similarly, impaired red/far red light perception also increased GLV emission. However, neither ABA treatment nor impairment of plant light perception had a significant effect on emission of terpenoids.

\section{Genes responsible for terpenoid and GLV biosynthesis are diurnally transcribed}

A previously published microarray data set revealed dynamic transcriptome changes in $N$. attenuata after $\mathrm{W}+$ $\mathrm{R}$ treatment [35]. From this data set, NaLIS transcripts, encoding the linalool synthase 23, were abundant in the daytime and barely detectable at night (Fig. 4A). Transcripts of the $(E)$ - $\alpha$-bergamotene synthase gene, NaTPS38 [24], were strongly increased in both day and night, however, the rate of up-regulation was greater during the day. Intriguingly, transcripts of NaHPL and NaLOX2, both involved in GLV biosynthesis, were also more abundant during the day, even though the emission of most GLVs is nocturnal. Using qRT-PCR we further confirmed that light deprivation strongly downregulated NaLIS transcript levels, as well as those of NaGPPS1 and NaGPPS2, genes responsible for the biosynthesis of monoterpenoid substrates upstream in the pathway (Fig. 4B).

\section{Cis-acting regulatory elements involved in light-, stress-, phytohormone- and circadian-regulation were identified in the biosynthetic genes}

We scanned the $2 \mathrm{~kb}$ promoter regions of NaLIS, NaTPS38, NaHPL and NaLOX2 for cis-acting regulatory elements (Fig. 5, Table 1, Table S2). NaLIS has six and NaTPS38 five elements identified as potentially involved in responsiveness to light in their promoters, and eight and fourteen were found in the promotors of NaHPL and NaLOX2, respectively. Box 4 [36] was present in all the promoters with different copy numbers. Some of the 


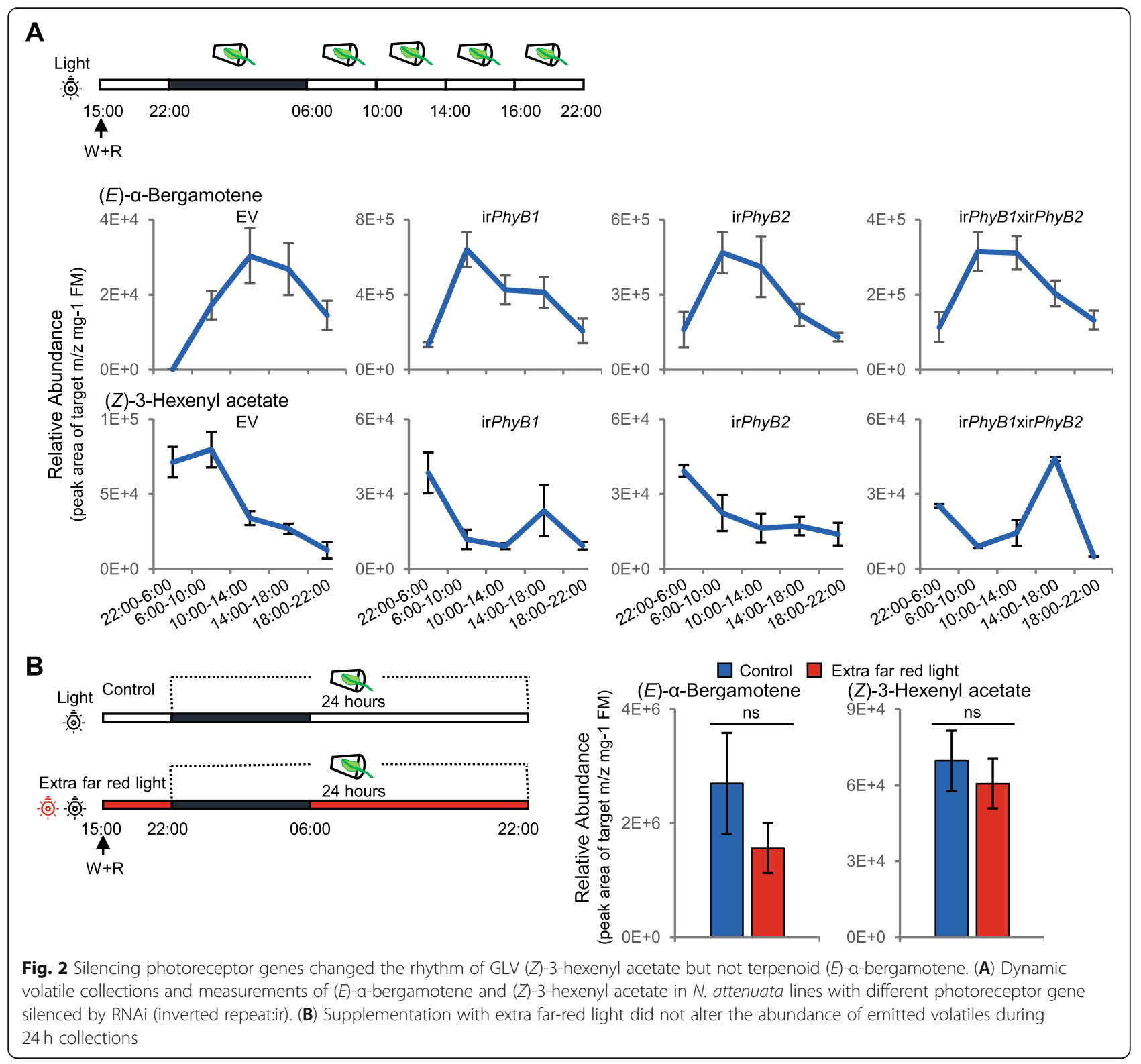

elements were found in two or three of the promoters such as the AE box [37], G-box [38, 39], GT1-motif [40], and TCT-motif [41]. The others were only found in a specific promoter, e.g. the ACE [42] element was only in the promoter of NaLOX, chs-CMA1a [43] in the promoter of NaLIS, GA-motif [44] and I-box [45] in the promoter of NaHPL. The promoter regions of these genes also contained numerous elements responsive tostress and/or phytohormones including JA, MeJA, SA and ABA, specifically: seven for NaLIS, eight for NaTPS38, 11 for NaHPL and 13 for NaLOX. Notably, the ABRE element (ACGTG/CACGTG/AACCCGG) involved in ABA regulation $[46,47]$ was specifically found in the NaLIS, NaHPL and NaLOX2 promotor regions, but not for NaTPS38. This is consistent with ABA treatment enhancing ( $Z$ )-3-hexenyl acetate emissions and internal pools, and decreasing linalool internal pools, but not affecting (E)- $\alpha$-bergamotene (Fig. 3D). A single circadian element (CAAAGATATC, [48]) was identified for NaLIS, NaTPS38, and NaLOX2, but not for NaHPL.

\section{Discussion}

HIPVs emitted from $N$. attenuata plants varied in composition and abundance across the day/night cycle. Terpenoid constituents of the volatile bouquet showed emissions which peaked in the middle of the day and responded quickly to light deprivation, while GLVs tended to be emitted more at night and were enhanced by light deprivation. Rhythms of the terpenoid volatiles 


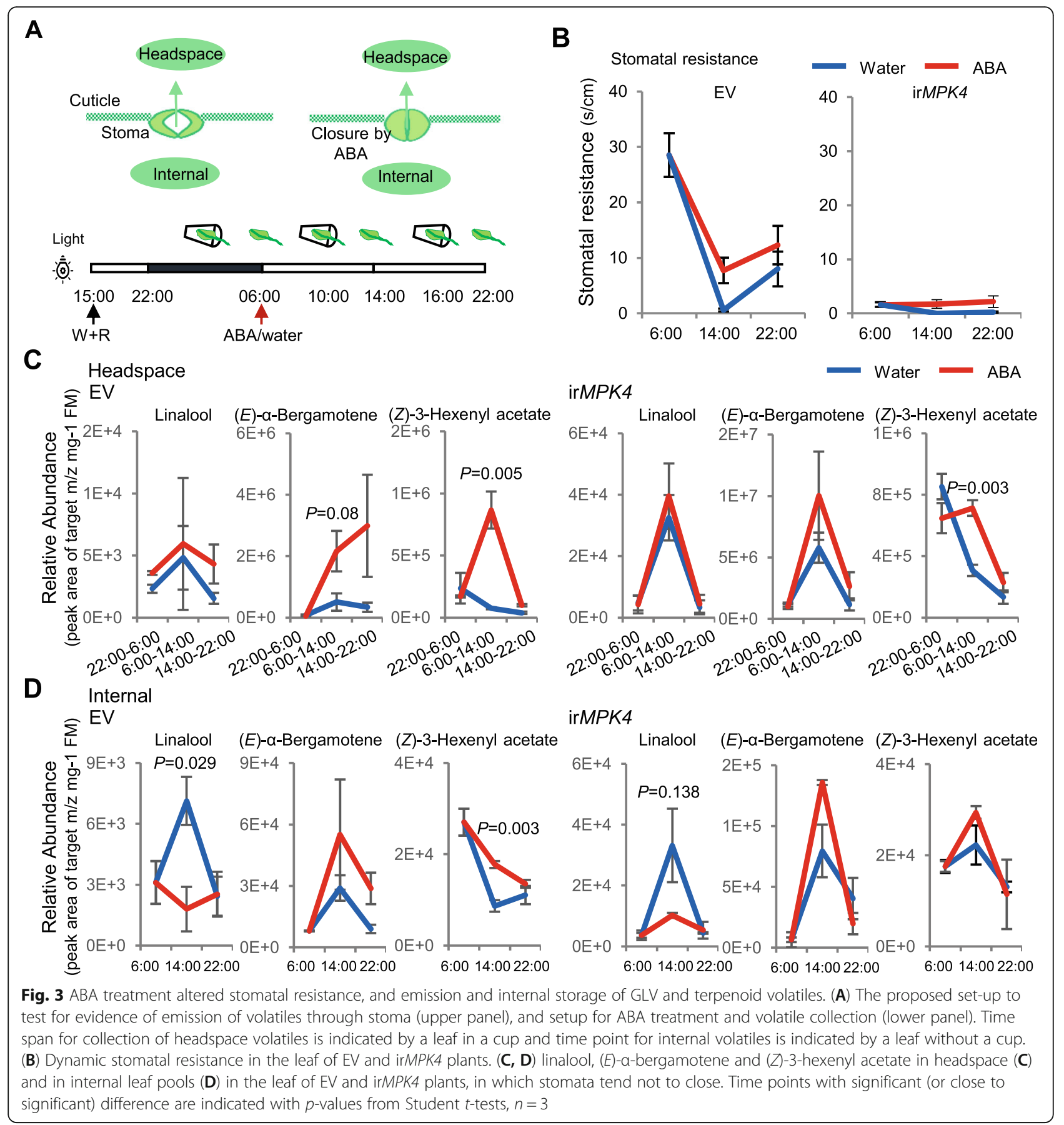

were not altered by the constitutive silencing of photoreceptor genes, supplementation by far-red light, or stomatal closure elicited by ABA treatments. GLV emissions, including (Z)-3-hexenyl acetate, were increased by $P h y B$ silencing and ABA treatments. Transcript abundances of the genes involved in the biosynthesis of terpenoids and GLVs varied over a day/ night cycle, and various light- or JA-responsive cis-acting regulatory elements, as well as some circadian clock and
ABA regulation elements were identified in their promoter regions.

\section{Correlations of HIPV emissions with herbivory and tri- trophic interactions}

In nature, plants must cope with environments characterized by periodic changes that accompany day/night cycles that include fluctuations in many factors in addition to light: temperature, humidity, and 


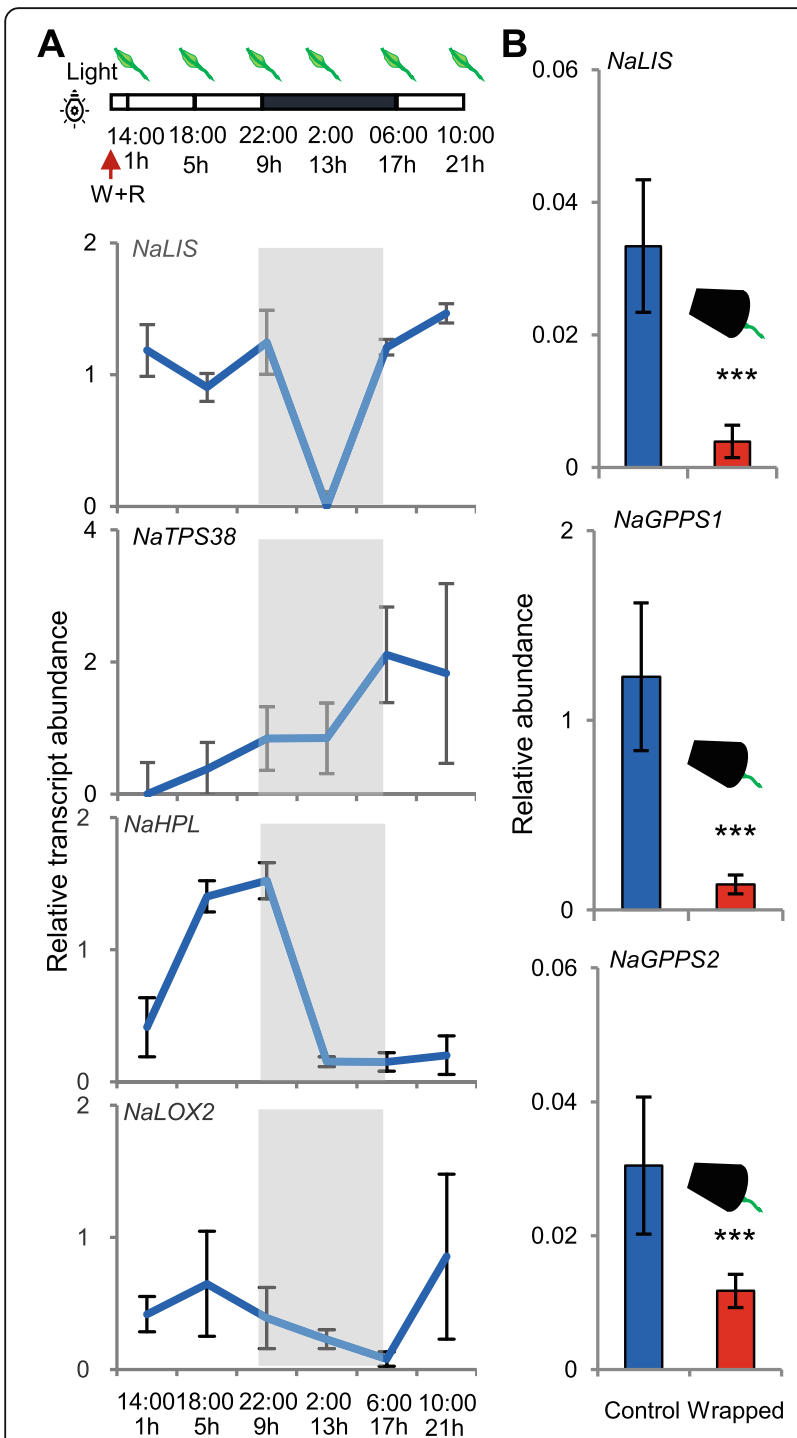

Fig. 4 Transcription of genes involved in biosynthesis of terpenoids and GLVs corresponding to illumination. (A) Transcript abundance of linalool synthase gene NaLIS and (E)-a-bergamotene synthase gene NaTPS38, and NaHPL and NaLOX2, which are involved in the biosynthesis of GLVs during $21 \mathrm{~h}$ after $\mathrm{W}+\mathrm{R}$ treatments. Data are from a published microarray data set (Kim et al. 2011). (B) Transcript abundance of NaLIS and two GPPSs, which are responsible for biosynthesis of the monoterpenoid substrate GPP, are downregulated in leaves enclosed in foil-wrapped cups. Measured with $\mathrm{QRT} T-\mathrm{PCR}$

innumerable biotic interactions. For instance, plants need to adopt to rhythms of attacks by pathogens and herbivores, or activity patterns of beneficial species, such as pollinators and natural enemies of herbivores $[4,6$, 57, 58]. To cope with this environmental rhythmicity, plants have evolved both endogenous rhythms and the ability to coordinate responses to changes in specific environmental factors. Much of this can be seen in changes in the abundance and composition of their metabolites
[59]. Different HIPV constituents of $N$. attenuata plants are associated with activities of different species that interact with the plants in nature. The larvae of the specialist Manduca spp. are known to feed diurnally. Experimental measures of predation rates of eggs and larvae were correlated with the diurnal emissions of terpenoid volatiles, which is consistent with previous reports by Joo et al. [28]. If we understand the mechanisms responsible for these emission patterns, these mechanisms could provide means of experimentally manipulating the patterns and hence provide a way to test such correlations observed in field studies.

\section{Rhythms of the emission of terpenoid volatiles and GLVs}

Herbivore-induced mono- or sesquiterpene terpenoids are diurnally regulated in many species such as G. hirsutum [60], A. апnиa [19], A. majus [61] and Phaseolus vulgaris [18] upon herbivory. Similarly, in $N$. attenuata at least $(E)$ - $\beta$-ocimene, $(E)$ - $\alpha$-bergamotene and linalool showed diurnal emission following herbivore elicitation $[22,23]$. Interestingly, $(E)$ - $\alpha$-bergamotene is diurnally emitted from foliage of $N$. attenuata plants and functions in attracting natural enemies that protect plants from herbivory by larvae of $M$. sexta. However, the same compound is nocturnally released from flowers and attracts adults of the same insect, which provides pollination services [24]. Further study showed that $(E)-\beta$ ocimene and $(E)$ - $\alpha$-bergamotene are correlated with each other across different $N$. attenuata genotypes, but linalool is independently regulated $[23,27]$. Furthermore, unlike the emission of linalool, the endogenous leaf pools of conjugates derived from linalool, such as linalool glycosides, lack the diurnal pattern of emissions [23].

In this study we confirmed the diurnal emission pattern of terpenoid volatiles, including $(E)$ - $\alpha$-bergamotene and linalool [28], and further found that this diurnal pattern was not altered by the silencing of photoreceptor genes or increased stomatal resistance resulting from ABA treatments. Interestingly, ABA treatment suppressed internal linalool, but had little influence on internal $(E)$ - $\alpha$-bergamotene. The contradictory influences of ABA treatments on emission and internal linalool might be attributed to opposing effects of ABA on biosynthesis or conjugation of linalool, and the mechanisms of the emission process.

In contrast to conserved diurnal emission of terpenoids across different species, GLVs showed both diurnal and nocturnal release. For example, mechanical damage to lima bean (Phaseolus lunatus) plants during the light phase induced high emissions of both $\beta$ ocimene and ( $Z$ )-3-hexenyl acetate, while damage during the night only upregulated the emission of $(Z)$-3-hexenyl acetate [20]. In elicited kidney bean, GLV (Z)-3-hexenol was abundantly emitted during the night while the 


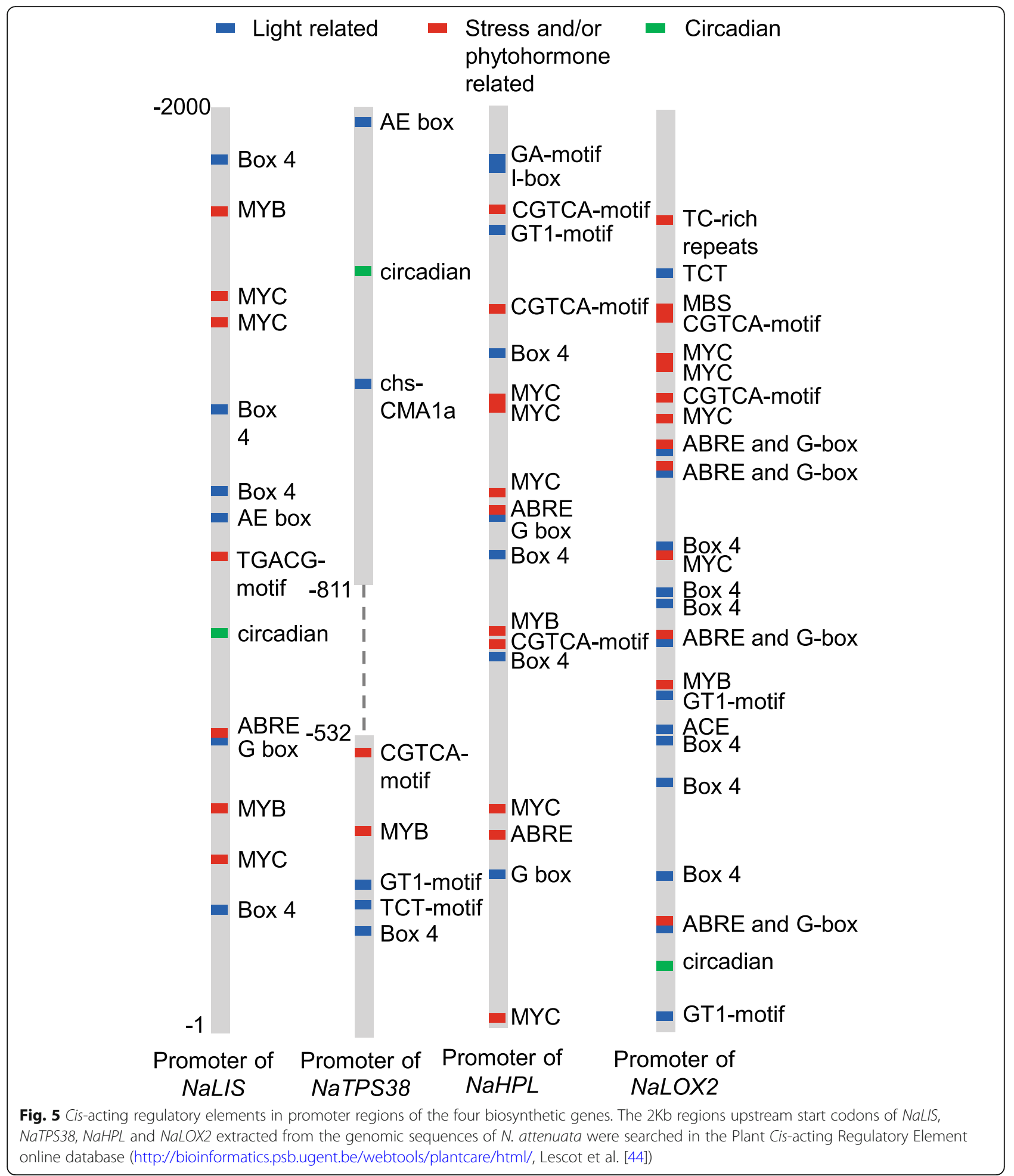

opposite was true for (Z)-3-hexenyl acetate [18]. In this study, we revealed a high nocturnal emission of GLVs, which is in agreement with previous studies [28, 29]. Additional work is required to understand the potential ecological significance of these opposing patterns for different constituents, and for these inferences, basic natural history information about the $N$. attenuata plants and activities of their surrounding organisms in the field plays a central role. For example, GLVs emitted during night might be used as feeding cues by 
Table 1 Cis-acting regulatory elements identified in the promoter sequences of NaLIS, NaTPS38, NaHPL and NaLOX

\begin{tabular}{|c|c|c|c|c|c|c|c|}
\hline \multirow[t]{2}{*}{ Name } & \multirow{2}{*}{$\begin{array}{l}\text { Consensus } \\
\text { sequences }\end{array}$} & \multicolumn{4}{|c|}{ Number of copies } & \multirow[t]{2}{*}{ Stimuli } & \multirow[t]{2}{*}{ Reference } \\
\hline & & $\begin{array}{l}\mathrm{Na} \\
\text { LIS* }\end{array}$ & $\begin{array}{l}\mathrm{Na} \\
\mathrm{TPS38}\end{array}$ & $\begin{array}{l}\mathrm{Na} \\
\mathrm{HPL}\end{array}$ & $\begin{array}{l}\mathrm{Na} \\
\mathrm{LOX}\end{array}$ & & \\
\hline ACE & GACACGTATG & & & & 1 & light & {$[42]$} \\
\hline AE-box & AGAAACAA & 1 & 1 & & & light & {$[37]$} \\
\hline Box 4 & ATTAAT & 4 & 1 & 3 & 6 & light & {$[36]$} \\
\hline chs-CMA1a & TTACTTAA & & 1 & & & light & [43] \\
\hline GA-motif & ATAGATAA & & & 1 & & light & {$[44]$} \\
\hline \multirow[t]{3}{*}{ G-box } & CACGTC/CACGTG/ & 1 & & 2 & 4 & light & {$[38,39]$} \\
\hline & CACGAC/ & & & & & & \\
\hline & CACGTT/TAAACGTG & & & & & & \\
\hline GT1-motif & GGTTAA & & 1 & 1 & 2 & light & {$[40]$} \\
\hline I-box & AGATAAGG & & & 1 & & light & {$[45]$} \\
\hline TCT-motif & TCTTAC & & 1 & & 1 & light & [41] \\
\hline \multirow[t]{2}{*}{ MYB } & CAACTG/CAACAG/ & 2 & 2 & 1 & 2 & $\mathrm{JA} /$ stress & {$[49,50]$} \\
\hline & TAACTG/TAACCA & & & & & & \\
\hline \multirow[t]{2}{*}{ MYC } & CATGTG/TCTCTTA/ & 3 & 3 & 5 & 4 & $\mathrm{JA} /$ stress & {$[49,51]$} \\
\hline & CAATTG/CATTTG & & & & & & \\
\hline CGTCA-motif & CGTCA & & 1 & 3 & 2 & MeJA & {$[52,53]$} \\
\hline TGACG-motif & TGACG & 1 & 1 & & & MeJA & {$[52,53]$} \\
\hline \multirow[t]{2}{*}{ ABRE } & ACGTG/CACGTG/ & 1 & & 2 & 4 & $\mathrm{ABA}$ & {$[46,47]$} \\
\hline & AACCCGG & & & & & & \\
\hline TC-rich repeats & GTTTCTTAC & & & & 1 & stress & [54] \\
\hline TCA-element & TCAGAAGAGG & & 1 & & & SA & {$[55,56]$} \\
\hline circadian & CAAAGATATC & 1 & 1 & & 1 & circadian & {$[48]$} \\
\hline
\end{tabular}

nocturnally active herbivores in the field, as has been shown for $M$. sexta larvae in both laboratory and field studies [62].

\section{Light is essential for the regulation of HIPVs}

A major conclusion of this study is that light strongly and locally regulates HIPV emissions, for both terpenoids and GLVs, although this could not be attributed directly to specific photoreceptors. This finding is consistent with earlier reports demonstrating that HIPV emissions from maize plants were light-dependent [63]. Light could influence the biosynthesis of terpenoids in at least two ways. First, pyruvate and glyceraldehyde 3phosphate, the precursors for terpene biosynthesis, are derived from the Calvin cycle $[64,65]$, which requires the immediate products of photosynthesis. For example, biosynthesis of $\beta$-ocimene in lima bean plants dependeds on the $\mathrm{CO}_{2}$ fixation by photosynthesis [20]. Perhaps this explains the immediate reduction of terpenoid emission by light deprivation in our study, because it shuts down the primary source of substrates for the terpenoid biosynthesis pathway. However, in the sink parts of a plant, such as floral tissues, the biosynthesis of terpenoids is not limited by photosynthesis, and $N$. attenuata flowers emit $(E)$ - $\alpha$-bergamotene during the night [24]. Second, light as signal, can regulate the expression of the genes involved in the biosynthesis of terpenoids. Light is necessary for the expression of genes in the MEP/DOXPpathway, which synthesizes the terpenoid precursors [66]. In seedlings of $A$. thaliana almost all the genes in the pathway are repressed in darkness [67]. In the current study, we also found that synthase genes of $(E)$ $\alpha$-bergamotene, linalool, and the precursor GPP had lower transcript levels or were less induced by herbivory during night, were also downregulated by light deprivation in the middle of the day, and were associated with light-responsive regulatory elements.

Surprisingly, we found that GLVs were also strongly and temporarily affected by light and ABA treatment in $N$. attenuata. In response to herbivory, the increase in GLV emissions is more rapid than the response in terpenoid volatiles $[28,68]$. Here, study, light deprivation in the middle of the day enhanced GLV emission with a delay during the subsequent hours, in contrast with the immediate reduction of terpenoid emission. This might be because the precursors for GLV biosynthesis, 
polyunsaturated fatty acids, are not immediate de novo products of photosynthesis. Therefore, light, probably together with the circadian clock, may affect biosynthesis of GLVs through regulating the expression of biosynthesis genes, with some delay in the accumulation of active proteins. This enhancement could be viewed as consistent with the effect of NaPhyB1 silencing in the down-regulation of GLV (Z)-3-hexenyl acetate emissions, and suggests that far-red light could function as a signal regulating GLV emissions. However, volatile collections from leaves exposed to supplemental far-red light did not support this inference, implying that the regulation might be very transient or occur only at a specific interval of the day/night cycle. Furthermore, we found that transcript levels of NaHPL and NaLOX2 sharply decreased at the start of the dark phase, in conflict with the higher nocturnal emission of most of the GLVs. These often contradictory results from physiological manipulations underscore the inference that emissions are under complex regulation. A detailed examination of the promotors of HIPV biosynthetic genes can be a valuable exercise so as to better understand the environmental factors that contribute to the patterns of transcript abundances.

\section{Complex regulation of HIPVs in $N$. attenuata}

HIPV emissions are known to be influenced by herbivory elicitation [7], light conditions, the endogenous circadian clock [61], temperature [69], water availability [70] and the still mysterious emission process [71]. Many volatiles are only emitted or increased emission upon elicitation such as by herbivory and mechanical damage $[67,72,73]$. These inductions are usually mediated by the JA signaling pathway [11, 29, 74-78]. The circadian clock is another major regulator of HIPVs. For instance, genes involved in the biosynthesis of terpenoid volatiles, including TPSs and the genes upstream in the pathways, are known to be regulated by circadian clock components $[61,64,65]$. The transcription of GLV biosynthesis genes, NaHPL and NaLOX2, is also regulated by the circadian clock [25, 29].

The cis-acting regulatory elements identified in the promoter regions of the synthase genes of terpenoids and GLVs provide additional evidence for the concerted regulation of these genes by herbivory, light and the circadian clock. Multiple stress- and phytohormonesignaling elements were identified in the promoter regions of the genes involved in terpenoid and GLV biosynthesis and could provide a means of coordinating HIPVs with other JA-, MeJA, SA, and ABA-mediated chemical defenses. A number of light responsive elements and circadian related elements were found for both terpenoid and GLV genes. Interestingly, an ABAresponsive element present in the promoter of NaLIS but not NaTPS38 might account for the specific suppression of NaLIS transcription and linalool biosynthesis by ABA treatments. These cis-acting regulatory elements suggests the regulation by different transcription factors that could coordinate HIPV biosynthesis with various environmental factors such as herbivory, light and the internal clock.

\section{Conclusions}

In summary, this study revealed that light is necessary for the full induction of terpenoid volatiles and the suppression of GLVs, and regulates the transcription of HIPV genes in concert with many other factors.

\section{Materials and methods}

\section{Plant materials and growth}

Plant seeds used in this study were from a seedbank of the Department of Molecular Ecology, MPICE (http:// www.ice.mpg.de/). The numbers of transgenic lines used in a glasshouse experiment are listed in Table S1. Plants grown in the field plot for the predation assay were the F12 generation of an advanced intercross-recombinant inbred line (AI-RIL) population [24], which was constructed from a cross between two inbred lines separately originating from collections in Arizona (AZ) and Utah (UT) by Baldwin and colleagues [79, 80]. The field experiments were performed at the Walnut Creek Center for Education and Research (WCCER)(34'55'17.8"N $\left.112^{\circ} 50^{\prime} 42.2^{\prime \prime} \mathrm{W}\right)$ located in Arizona, southwestern United States. The plants grown in the field are native to the area, not endangered species, non-transgenic material and non-regulated. No samples were collected from the wild. The field experiments were permitted and supported by WCCER. Seeds were germinated on Gamborg's B5 medium in Petri dishes under conditions previously described by Krügel and colleagues [81]. Two weeks later, seedlings were transferred into peat plugs (Jiffy 703, www.jiffypot.com). During the next 2 weeks seedlings were increasingly exposed to outdoor conditions and subsequently transplanted into the field plot. The plants were watered regularly by a drip irrigation system [82].

Plants used for the different light treatments and dynamic volatile collections were grown in a glasshouse. The generation and screening of the transgenic lines (listed in Table S1) silenced in the expression of photoreceptor genes and NaMPK4 were previously described $[31,34]$. Seedlings were germinated in the described way and transferred into potting soil (www.klasmanndeilmann.com) in small pots (TEKU JJP 3050104 pots, Poeppelmann GmbH \& Co. KG, Lohne, Germany) for 10 days and then transplanted into $1 \mathrm{~L}$ pots and kept in a glasshouse $\left(19{ }^{\circ} \mathrm{C}-35^{\circ} \mathrm{C}, 55 \%\right.$ humidity, light period: 6 : 00-22:00, supplemental lighting by Philips Sun-T Agro 
$400 \mathrm{~W}$ and $600 \mathrm{~W}$ sodium lights) [81, 83]. Plants were watered and fertilized as previously described by Schuman et al. [84]. Experimental research and field studies on plants complies with relevant institutional, national, and international guidelines and legislation.

\section{M. sexta rearing and regurgitant collection}

$M$. sexta used in this study were from an in-house colony maintained on artificial diet (Bell RA \& Joachim FG 1976) in a climate chamber $\left(24^{\circ} \mathrm{C}\right.$, light period: 0:00 to 13:00, relative humidity: 70\%). For collection of regurgitant, caterpillars were reared on $N$. attenuata UT WT plants. Collection and storage of regurgitant were previously described $[78,85]$.

\section{W + R treatment and headspace sampling}

The first stem leaf of elongated plants was chosen for elicitation with wounding by a pattern wheel and the immediate addition of $20 \mu \mathrm{L}$ of $20 \%$ diluted regurgitant in water to the puncture wounds in the leaf lamina. The treated leaf was gently rubbed with fingers in clean gloves. This leaf was enclosed in a ventilated PET cup (ca. $650 \mathrm{~mL}$ ). Headspace volatiles were collected as described by Kallenbach et al. [30] with two pieces of silicone laboratory tubing (ST, $1 \mathrm{~mm}$ i.d. $\times 1.8 \mathrm{~mm}$ o.d.; Carl Roth, catalog number: $9555.1 ; 5 \mathrm{~mm}$ for each piece) placed into the cup under the leaf for $4 \mathrm{~h}$ (time-resolved) or $24 \mathrm{~h}$ (long term collection). For the quantification of internal volatile pools, the sampled leaf was flash-frozen and ground in liquid $\mathrm{N}_{2}$. One hundred $\mathrm{mg}$ tissue was placed into a $1.5 \mathrm{~mL}$ glass GC vial (Sigma-Aldrich) and $0.8 \mathrm{~mL}$ saturated $\mathrm{CaCl}_{2}$ solution was added. One piece of ST was placed into the vial and fully immersed into the solution to extract free volatiles [29]. STs with collected volatiles were stored in a clean glass vial in $-20^{\circ} \mathrm{C}$ freezer.

\section{Light deprivation, far-red supplementation and ABA treatment}

Temporary, local light deprivation was applied to elicited leaves by wrapping the collection cup with aluminum foil. Temperature and humidity in the glasshouse, clean and wrapped cup were recorded by PRO-USB-2 data Logger with humidity, temperature sensor (RS Components $\mathrm{GmbH}$ ). Additional far-red was supplied as previously described [31]: five-Watt far-red light emitting diodes (LED, $720 \pm 10 \mathrm{~nm}$ ) were directed to the adaxial side of the targeted leaf. ABA (Sigma-Aldrich) was diluted to $2 \mu \mathrm{M}$ and sprayed on the leaf in the morning at around 6:00. Stomatal resistance was measured by an AP4 Porometer (AP4-UM-3, Delta-T Devices) following the manufacturer's instructions.

\section{TD-GC-QMS analysis}

STs with absorbed volatiles were analyzed on a quadrupole GC-MS-QP2010Ultra equipped with a TD-20 thermal desorption unit (Shimadzu). Desorption and analysis were performed as previously described [30]. Peaks were integrated using the target and reference ions as previously described [23] and tentative compound identifications were based on comparison with an in-house library of $N$. attenuata volatiles prepared in the same lab including the spectra, retention times and relative retention orders of these volatiles from standards and samples analyzed using the same method. Identification of volatiles in the reference library was based on pure standards, Kovats retention indices and comparison of spectra to NIST MS libraries [30].

\section{Measuring transcript abundance of genes}

The transcription levels of NaLIS, NaGPPS1 and NaGPPS2 in leaves under standard light or light deprivation conditions were quantified using qPCR as previously described [23]. Total RNA was extracted using the NucleoSpin ${ }^{\circ}$ RNA Plant kit (MACHEREYNAGEL). After digestion of genomic DNA, $1 \mu \mathrm{g}$ total RNA was transcribed with the PrimeScript ${ }^{\text {tim }}$ RT reagent Kit (TAKARA). Primer sequences were described previously [23] and the qPCR was run in a MX3005P PCR cycler (Stratagene).

\section{Identification of cis-acting regulatory elements}

The $2 \mathrm{~Kb}$ sequences upstream of the start codons of NaLIS, NaTPS38, NaHPL and NaLOX2 were extracted from the genomic sequences of $N$. attenuata [86]. Then these sequences were searched online through the Plant Cis-acting Regulatory Element database (http:// bioinformatics.psb.ugent.be/webtools/plantcare/html/, Lescot et al. [2002]).

\section{Abbreviations \\ ABA: Abscisic acid; Crypt: Cryptochrome; GLV: Green leaf volatiles; GPPS: Geranylgeranyl diphosphate synthase; HIPV: Herbivore-induced plant volatile; HPL: Hydroperoxide lyase; JA: Jasmonate; LIS: Linalool synthase; LOX: Lipoxygenase; MeJA: Methyl jasmonate; MPK4: Mitogen-activated protein kinase 4; PhyA: Phytochrome A; PhyB: Phytochrome B; SA: Salicylic acid; TPS: Terpene synthase; $W+R$ : Wounding plus $M$. sexta larval regurgitant}

\section{Supplementary Information}

The online version contains supplementary material available at https://doi. org/10.1186/s12870-021-03179-z.

\footnotetext{
Additional file 1 Fig. S1. Diurnal predation of eggs and larvae of $M$. sexta feeding on $N$. attenuata plants. (A) Diagram of natural predators (like Geocoris spp.) capture preys (such as $M$. sexta larvae and eggs) on $N$. attenuata plants. (B) Number of predated eggs and larvae of $M$. sexta observed in a field plot of $N$. attenuata plants during day or night periods. Fig. S2. Difference in temperature and humidity caused by wrapping the collecting cups. Fig. S3. Volatile emissions in plants with NaCrypt and NaCrypt2 silenced (related to Fig. 2). Fig. S4.

Supplementation with extra far-red light did not alter the dynamics of
} 
volatile emissions. Table S1. Transgenic lines used in this study. Table S2. Detailed information of cis-acting regulatory elements identified in the promoter sequences of NaLIS, NaTPS38, NaHPL and NaLOX.

\section{Acknowledgements}

The authors thank Prescott College, Northern Arizona University, the Arboretum at Flagstaff, Prescott National Forest, and the Southwest Experimental Garden Array for the use of a field plot at the Walnut Creek Center for Education and Research; R. and N. Carlson and the Southwest Experimental Garden Array staff for assistance with field plantations, Dr. X. Wang for discussion and critical comments.

\section{Authors' contributions}

J.H., R.H., I.T.B. and M.C.S. conceptualized the project; R.H., I.T.B. and M.C.S. administrated the project and supervised the research; I.T.B. and M.C.S. acquired the funding and resources; J.H. and R.H. did investigation; J.H. wrote the original draft, which R.H., M.C.S., and I.T.B. reviewed \& edited: All authors read and approved the final manuscript.

\section{Funding}

This work was funded by the Max Planck Society and Advanced Grant 293926 of the European Research Council (to I.T.B.), and in part supported by the Collaborative Research Centre ChemBioSys (CRC 1127) funded by the Deutsche Forschungsgemeinschaft, and Fundamental Research Funds for the Central Universities (SWU120067), and the Venture \& Innovation Support Program for Chongqing Overseas Returnees (7820100514). The funders payed the associated experimental costs and publication fees, but had no role in the design of the study and collection, analysis, and interpretation of data and in writing the manuscript. Open Access funding enabled and organized by Projekt DEAL.

\section{Availability of data and materials}

The datasets used and/or analysed during the current study are available from the corresponding author on reasonable request.

\section{Declarations}

Ethics approval and consent to participate Not applicable.

\section{Consent for publication}

Not applicable.

\section{Competing interests}

The authors declare that they have no competing interests.

\section{Author details}

${ }^{1}$ National Citrus Engineering Research Center, Citrus Research Institute, Southwest University, Xiema Street, Beibei, Chongqing 400712, People's Republic of China. ${ }^{2}$ Department of Molecular Ecology, Max Planck Institute for Chemical Ecology, Hans-Knöll-Straße 8, 07745 Jena, Germany. ${ }^{3}$ Current address: Departments of Geography and Chemistry, University of Zurich, 8057 Zürich, Switzerland.

\section{Received: 6 April 2021 Accepted: 9 August 2021}

Published online: 30 August 2021

\section{References}

1. Pruneda-Paz JL, Kay SA. An expanding universe of circadian networks in higher plants. Trends Plant Sci. 2010;15(5):259-65. https://doi.org/10.1016/j. tplants.2010.03.003.

2. Kolosova N, Gorenstein N, Kish CM, Dudareva N. Regulation of circadian methyl benzoate emission in diurnally and nocturnally emitting plants. Plant Cell. 2001;13(10):2333-47. https://doi.org/10.1105/tpc.010162.

3. Hoballah ME, Stuurman J, Turlings TCJ, Guerin PM, Connétable S, Kuhlemeier $\mathrm{C}$. The composition and timing of flower odour emission by wild Petunia axillaris coincide with the antennal perception and nocturnal activity of the pollinator Manduca sexta. Planta. 2005;222(1):141-50. https:// doi.org/10.1007/s00425-005-1506-8.
4. Goodspeed D, Chehab EW, Min-Venditti A, Braam J. Covington MF Arabidopsis synchronizes jasmonate-mediated defense with insect circadian behavior. P Natl Acad Sci USA. 2012;109(12):4674-7. https://doi.org/10.1073/ pnas.1116368109.

5. Wang W, Barnaby JY, Tada Y, Li H, Tor M, Caldelari D, et al. Timing of plant immune responses by a central circadian regulator. Nature. 2011:470(7332): 110-U126. https://doi.org/10.1038/nature09766.

6. Hevia MA, Canessa P, Muller-Esparza H, Larrondo LF. A circadian oscillator in the fungus Botrytis cinerea regulates virulence when infecting Arabidopsis thaliana. P Natl Acad Sci USA. 2015;112(28):8744-9. https://doi.org/10.1073/ pnas.1508432112.

7. Baldwin IT. Plant volatiles. Curr Biol. 2010;20(9):R392-7. https://doi.org/10.101 6/j.cub.2010.02.052.

8. Loreto F, Dicke M, Schnitzler JP, TCJ T. Plant volatiles and the environment. Plant Cell Environ. 2014:37(8):1905-8. https://doi.org/10.1111/pce.12369.

9. Paré PW, Tumlinson JH. De novo biosynthesis of volatiles induced by insect herbivory in cotton plants. Plant Physiol. 1997;114(4):1161-7. https://doi. org/10.1104/pp.114.4.1161

10. Scala A, Allmann S, Mirabella R, Haring MA, Schuurink RC. Green leaf volatiles: a plant's multifunctional weapon against herbivores and pathogens. Int J Mol Sci. 2013;14(9):17781-811. https://doi.org/10.3390/ ijms140917781.

11. Schuman MC, Heinzel N, Gaquerel E, Svatos A, Baldwin IT. Polymorphism in jasmonate signaling partially accounts for the variety of volatiles produced by Nicotiana attenuata plants in a native population. New Phytol. 2009; 183(4):1134-48. https://doi.org/10.1111/j.1469-8137.2009.02894.x.

12. Allmann S, Baldwin IT. Insects betray themselves in nature to predators by rapid isomerization of green leaf volatiles. Science. 2010;329(5995):1075-8. https://doi.org/10.1126/science.1191634.

13. Boonprab K, Matsui K, Akakabe Y, Yotsukura N, Kajiwara T. Hydroperoxyarachidonic acid mediated n-hexanal and (Z)-3- and (E)-2-nonenal formation in Laminaria angustata. Phytochemistry. 2003:63(6):669-78. https://doi.org/10.1016/S0031-9422(03)00026-8.

14. Chen HM, Zhu ZJ, Chen Jل Jang R, Luo Q O Xu J, et al. A multifunctional lipoxygenase from Pyropia haitanensis-the cloned and functioned complex eukaryotic algae oxylipin pathway enzyme. Algal Res-Bio Biofuels Bioproduct. 2015;12:316-27.

15. Chen F, Tholl D, Bohlmann J, Pichersky E. The family of terpene synthases in plants: a mid-size family of genes for specialized metabolism that is highly diversified throughout the kingdom. Plant J. 2011;66(1):212-29. https://doi. org/10.1111/j.1365-313X.2011.04520.x.

16. Kuzuyama T, Seto H. Two distinct pathways for essential metabolic precursors for isoprenoid biosynthesis. Proc Jpn Acad Ser B Phys Biol Sci. 2012;88(3):41-52. https://doi.org/10.2183/pjab.88.41.

17. Martin DM, Gershenzon J, Bohlmann J. Induction of volatile terpene biosynthesis and diurnal emission by methyl jasmonate in foliage of Norway spruce. Plant Physiol. 2003;132(3):1586-99. https://doi.org/10.1104/ pp.103.021196.

18. Sufang Z, Jianing W, Zhen Z, Le K. Rhythms of volatiles release from healthy and insect-damaged Phaseolus vulgaris. Plant Signal Behav. 2013;8(10) https://doi.org/10.4161/psb.25759.

19. Lu S, Xu R, Jia JW, Pang J, Matsuda SP, Chen XY. Cloning and functional characterization of a $\beta$-pinene synthase from Artemisia annua that shows a circadian pattern of expression. Plant Physiol. 2002;130(1):477-86. https:// doi.org/10.1104/pp.006544.

20. Arimura Gl, Kopke S, Kunert M, Volpe V, David A, Brand P, et al. Effects of feeding Spodoptera littoralis on lima bean leaves: IV. Diurnal and nocturnal damage differentially initiate plant volatile emission. Plant Physiol. 2008; 146(3):965-73. https://doi.org/10.1104/pp.107.111088.

21. De Moraes CM, Mescher MC, Tumlinson JH. Caterpillar-induced nocturnal plant volatiles repel conspecific females. Nature. 2001;410(6828):577-80. https://doi.org/10.1038/35069058.

22. Halitschke R, Kessler A, Kahl J, Lorenz A, Baldwin IT. Ecophysiological comparison of direct and indirect defenses in Nicotiana attenuata. Oecologia. 2000;124(3):408-17. https://doi.org/10.1007/s004420000389.

23. He J, Fandino RA, Halitschke R, Luck K, Kollner TG, Murdock MH, et al. An unbiased approach elucidates variation in (S)-(+)-linalool, a context-specific mediator of a tri-trophic interaction in wild tobacco. P Natl Acad Sci USA 2019;116(29):14651-60. https://doi.org/10.1073/pnas.1818585116.

24. Zhou WW, Kügler A, McGale E, Haverkamp A, Knaden M, Guo H, et al. Tissue-specific emission of (E)-a-bergamotene helps resolve the dilemma 
when pollinators are also herbivores. Curr Biol. 2017;27(9):1336-41. https:// doi.org/10.1016/j.cub.2017.03.017.

25. Joo Y, Goldberg JK, Chretien LTS, Kim SG, Baldwin IT, Schuman MC. The circadian clock contributes to diurnal patterns of plant indirect defense in nature. J Integr Plant Biol. 2019;61 (8):924-8. https://doi.org/10.1111/jipb.12725.

26. Kessler A, Baldwin IT. Defensive function of herbivore-induced plant volatile emissions in nature. Science. 2001;291(5511):2141-4. https://doi.org/10.1126/ science.291.5511.2141.

27. Xu SQ, Kreitzer C, McGale E, Lackus ND, Guo H, Kollner TG, et al. Allelic differences of clustered terpene synthases contribute to correlated intraspecific variation of floral and herbivory-induced volatiles in a wild tobacco. New Phytol. 2020;228(3):1083-96. https://doi.org/10.1111/nph.16739.

28. Joo Y, Schuman MC, Goldberg JK, Kim SG, Yon F, Brutting C, et al. Herbivore-induced volatile blends with both "fast" and "slow" components provide robust indirect defence in nature. Funct Ecol. 2018;32(1):136-49. https://doi.org/10.1111/1365-2435.12947.

29. Joo Y, Schuman MC, Goldberg JK, Wissgott A, Kim SG, Baldwin IT. Herbivory elicits changes in green leaf volatile production via jasmonate signaling and the circadian clock. Plant Cell Environ. 2019;42(3):972-82. https://doi.org/1 $0.1111 /$ pce.13474.

30. Kallenbach M, Oh Y, Eilers EJ, Veit D, Baldwin IT, Schuman MC. A robust, simple, high-throughput technique for time-resolved plant volatile analysis in field experiments. Plant J. 2014;78(6):1060-72. https://doi.org/10.1111/ tpj.12523.

31. Oh Y, Fragoso V, Guzzonato F, Kim S-G, Park C-M, Baldwin IT. Rootexpressed phytochromes B1 and B2, but not PhyA and Cry2, regulate shoot growth in nature. Plant Cell Environ. 2018;41(11):2577-88. https://doi.org/1 $0.1111 /$ pce. 13341 .

32. Jones AC, Seidl-Adams I, Engelberth J, Hunter C, Alborn H, Tumlinson JH. Herbivorous caterpillars can utilize three mechanisms to alter green leaf volatile emission. Environ Entomol. 2019;48(2):419-25. https://doi.org/10.1 093/ee/nvy191.

33. Lin PA, Chen YT, Chaverra-Rodriguez D, Heu CC, Bin Zainuddin N, Sidhu JS, et al. Silencing the alarm: an insect salivary enzyme closes plant stomata and inhibits volatile release. New Phytol. 2021;230(2):793-803. https://doi. org/10.1111/nph.17214.

34. Hettenhausen C, Baldwin IT, Wu J. Silencing MPK4 in Nicotiana attenuata enhances photosynthesis and seed production but compromises abscisic acid-induced stomatal closure and guard cell-mediated resistance to pseudomonas syringae pv tomato DC3000. Plant Physiol. 2012;158(2):75976. https://doi.org/10.1104/pp.111.190074.

35. Kim SG, Yon F, Gaquerel E, Gulati J, Baldwin IT. Tissue specific diurnal rhythms of metabolites and their regulation during herbivore attack in a native tobacco, Nicotiana attenuata. PLoS One. 2011;6(10):e26214.

36. Schulze-Lefert P, Dangl JL, Beckerandre M, Hahlbrock K, Schulz W. Inducible invivo DNA footprints define sequences necessary for uv-light activation of the parsley chalcone synthase gene. EMBO J. 1989;8(3):651-6. https://doi. org/10.1002/j.1460-2075.1989.tb03422.x.

37. Park SC, Kwon HB. Shih MC Cis-acting elements essential for light regulation of the nuclear gene encoding the a subunit of chloroplast glyceraldehyde 3-phosphate dehydrogenase in Arabidopsis thaliana. Plant Physiol. 1996: 112(4):1563-71. https://doi.org/10.1104/pp.112.4.1563.

38. Giuliano G, Pichersky E, Malik VS, Timko MP, Scolnik PA. Cashmore AR an evolutionarily conserved protein-binding sequence upstream of a plant light-regulated gene. P Natl Acad Sci USA. 1988;85(19):7089-93. https://doi. org/10.1073/pnas.85.19.7089.

39. Huang $D$, Yuan $Y$, Tang Z, Huang $Y$, Kang $C$, Deng $X$, et al. Retrotransposon promoter of Ruby 1 controls both light- and cold-induced accumulation of anthocyanins in blood orange. Plant Cell Environ. 2019;42(11):3092-104. https://doi.org/10.1111/pce.13609.

40. Zhou DX. Regulatory mechanism of plant gene transcription by GTelements and GT-factors. Trends Plant Sci. 1999;4(6):210-4. https://doi.org/1 0.1016/S1360-1385(99)01418-1.

41. Wang LK, Li LS, Xu LN, Zhou J, Zhuang HH, Gong XD, et al. Isolation and functional analysis of the poplar RbcS gene promoter. Plant Mol Biol Rep. 2013;31(1):120-7. https://doi.org/10.1007/s11105-012-0482-y.

42. Weisshaar B, Armstrong GA, Block A, da Costa e Silva O, Hahlbrock K. Lightinducible and constitutively expressed DNA-binding proteins recognizing a plant promoter element with functional relevance in light responsiveness. EMBO J. 1991;10(7):1777-86. https://doi.org/10.1002/j.1460-2075.1991. tb07702.x.
43. Almasia NI, Narhirnak V, Hopp HE, Vazquez-Rovere C. Isolation and characterization of the tissue and development-specific potato snakin-1 promoter inducible by temperature and wounding. Electron J Biotechn. 2010;13(5).

44. Lescot M, Dehais P, Thijs G, Marchal K, Moreau Y, Van de Peer $Y$, et al. PlantCARE, a database of plant cis-acting regulatory elements and a portal to tools for in silico analysis of promoter sequences. Nucleic Acids Res. 2002;30(1):325-7. https://doi.org/10.1093/nar/30.1.325.

45. Hiratsuka K, Chua NH. Light regulated transcription in higher plants. J Plant Res. 1997;110(1097):131-9. https://doi.org/10.1007/BF02506852.

46. Kaplan B, Davydov O, Knight H, Galon Y, Knight MR, Fluhr R, et al. Rapid transcriptome changes induced by cytosolic Ca2+ transients reveal ABRErelated sequences as Ca2+-responsive cis elements in Arabidopsis. Plant Cell. 2006;18(10):2733-48. https://doi.org/10.1105/tpc.106.042713.

47. Guiltinan MJ, Marcotte WR, Quatrano RS. A plant leucine zipper protein that recognizes an abscisic-acid response element. Science. 1990;250(4978):26771. https://doi.org/10.1126/science.2145628.

48. Piechulla B, Merforth N, Rudolph B. Identification of tomato Lhc promoter regions necessary for circadian expression. Plant Mol Biol. 1998;38(4):655-62. https://doi.org/10.1023/A:1006094015513.

49. Abe H, Yamaguchi-Shinozaki K, Urao T, Iwasaki T, Hosokawa D, Shinozaki K. Role of arabidopsis MYC and MYB homologs in drought- and abscisic acidregulated gene expression. Plant Cell. 1997;9(10):1859-68. https://doi.org/1 $0.1105 /$ tpc. 9.10 .1859

50. Gigolashvili T, Berger B, Mock HP, Muller C, Weisshaar B, Fluegge UI. The transcription factor HIG1/MYB51 regulates indolic glucosinolate biosynthesis in Arabidopsis thaliana. Plant J. 2007;50(5):886-901. https://doi.org/10.1111/ j.1365-313X.2007.03099.x.

51. Chini A, Boter M, Solano R. Plant oxylipins: COI1/JAZs/MYC2 as the core jasmonic acid-signalling module. FEBS J. 2009;276(17):4682-92. https://doi. org/10.1111/j.1742-4658.2009.07194.X.

52. Kim SR, Kim YH, An GH. Identification of methyl jasmonate and salicylic-acid response elements from the nopaline synthase (nos) promoter. Plant Physiol. 1993;103(1):97-103. https://doi.org/10.1104/pp.103.1.97.

53. Rouster J, Leah R, Mundy J, CameronMills V. Identification of a methyl jasmonate-responsive region in the promoter of a lipoxygenase 1 gene expressed in barley grain. Plant J. 1997;11(3):513-23. https://doi.org/10.1046/ j.1365-313X.1997.11030513.x.

54. Klotz KL, Lagrimini LM. Phytohormone control of the tobacco anionic peroxidase promoter. Plant Mol Biol. 1996;31(3):565-73. https://doi.org/10.1 007/BF00042229.

55. Salazar M, Gonzalez E, Casaretto JA, Casacuberta JM, Ruiz-Lara S. The promoter of the TLC1.1 retrotransposon from Solanum chilense is activated by multiple stress-related signaling molecules. Plant Cell Rep. 2007;26(10): 1861-8. https://doi.org/10.1007/s00299-007-0375-y.

56. Goldsbrough AP, Albrecht H, Stratford R. Salicylic acid-inducible binding of a tobacco nuclear-protein to a 10-bp sequence which is highly conserved amongst stress-inducible genes. Plant J. 1993;3(4):563-71. https://doi.org/1 0.1046/j.1365-313X.1993.03040563.X.

57. Liu J, Chafi R, Legarrea S, Alba JM, Meijer T, Menken SBJ, et al. Spider mites cause more damage to tomato in the dark when induced defenses are lower. J Chem Ecol. 2020;46(7):631-41. https://doi.org/10.1007/s10886-02001195-1.

58. Borges RM, Bessière J-M, Ranganathan Y. Diel variation in fig volatiles across syconium development: making sense of scents. J Chem Ecol. 2013;39(5): 630-42. https://doi.org/10.1007/s10886-013-0280-5.

59. Liebelt DJ, Jordan JT, Doherty CJ. Only a matter of time: the impact of daily and seasonal rhythms on phytochemicals. Phytochem Rev. 2019;18(6):140933. https://doi.org/10.1007/s11101-019-09617-z.

60. Loughrin JH, Manukian A, Heath RR, Turlings TC, Tumlinson JH. Diurnal cycle of emission of induced volatile terpenoids by herbivore-injured cotton plant. Proc Natl Acad Sci. 1994;91(25):11836-40. https://doi.org/10.1073/pna S.91.25.11836.

61. Dudareva N, Andersson S, Orlova I, Gatto N, Reichelt M, Rhodes D, et al. The nonmevalonate pathway supports both monoterpene and sesquiterpene formation in snapdragon flowers. Proc Natl Acad Sci U S A. 2005;102(3):9338. https://doi.org/10.1073/pnas.0407360102.

62. Halitschke R, Stenberg JA, Kessler D, Kessler A, Baldwin IT. Shared signals 'alarm calls' from plants increase apparency to herbivores and their enemies in nature. Ecol Lett. 2008;11(1):24-34. https://doi.org/10.1111/j.1461-0248.2 007.01123.x. 
63. Gouinguené SP, TCJ T. The effects of abiotic factors on induced volatile emissions in corn plants. Plant Physiol. 2002;129(3):1296-307. https://doi. org/10.1104/pp.001941.

64. Cordoba E, Salmi M, Leon P. Unravelling the regulatory mechanisms that modulate the MEP pathway in higher plants. J Exp Bot. 2009;60(10):2933-43. https://doi.org/10.1093/jxb/erp190.

65. Pokhilko A, Bou-Torrent J, Pulido P, Rodriguez-Concepcion M, Ebenhoh O. Mathematical modelling of the diurnal regulation of the MEP pathway in Arabidopsis. New Phytol. 2015;206(3):1075-85. https://doi.org/10.1111/ nph.13258.

66. Hemmerlin A, Harwood JL, Bach TJ. A raison d'etre for two distinct pathways in the early steps of plant isoprenoid biosynthesis? Prog Lipid Res. 2012;51(2):95-148. https://doi.org/10.1016/j.plipres.2011.12.001.

67. Hsieh MH, Goodman HM. The Arabidopsis IspH homolog is involved in the plastid nonmevalonate pathway of isoprenoid biosynthesis. Plant Physiol. 2005;138(2):641-53. https://doi.org/10.1104/pp.104.058735.

68. Turlings TCJ, Lengwiler UB, Bernasconi ML, Wechsler D. Timing of induced volatile emissions in maize seedlings. Planta. 1998;207(1):146-52. https://doi. org/10.1007/s004250050466.

69. Ibrahim MA, Maenpaa M, Hassinen V, Kontunen-Soppela S, Malec L, Rousi $M$, et al. Elevation of night-time temperature increases terpenoid emissions from Betula pendula and Populus tremula. J Exp Bot. 2010;61(6):1583-95. https://doi.org/10.1093/jxb/erq034.

70. Lavoir AV, Staudt M, Schnitzler JP, Landais D, Massol F, Rocheteau A, et al. Drought reduced monoterpene emissions from the evergreen Mediterranean oak Quercus ilex: results from a throughfall displacement experiment. Biogeosciences. 2009;6(7):1167-80. https://doi.org/10.5194/bg6-1167-2009.

71. Widhalm JR, Jaini R, Morgan JA, Dudareva N. Rethinking how volatiles are released from plant cells. Trends Plant Sci. 2015;20(9):545-50. https://doi. org/10.1016/j.tplants.2015.06.009.

72. Dicke M, Sabelis MW. How plants obtain predatory mites as bodyguards Neth J Zool. 1988;38(2-4):148-65.

73. Gaquerel E, Weinhold A, Baldwin IT. Molecular interactions between the specialist herbivore Manduca sexta (lepidoptera, sphigidae) and its natural host Nicotiana attenuata. VIII. An unbiased GCxGC-ToFMS analysis of the plant's elicited volatile emissions. Plant Physiol. 2009;149(3):1408-23. https:// doi.org/10.1104/pp.108.130799.

74. Dicke M, Gols R, Ludeking D, Posthumus MA. Jasmonic acid and herbivory differentially induce carnivore-attracting plant volatiles in lima bean plants. J Chem Ecol. 1999;25(8):1907-22. https://doi.org/10.1023/A:1020942102181.

75. Miyazaki J, Stiller WN, Truong TT, Xu Q, Hocart CH, Wilson LJ, et al. Jasmonic acid is associated with resistance to twospotted spider mites in diploid cotton (Gossypium arboreum). Funct Plant Biol. 2014;41(7):748-57. https:// doi.org/10.1071/FP13333.

76. He J, Bouwmeester HJ, Dicke M, Kappers IF. Transcriptional and metabolite analysis reveal a shift in direct and indirect defences in response to spidermite infestation in cucumber (Cucumis sativus). Plant Mol Biol. 2020;103(45):489-505. https://doi.org/10.1007/s11103-020-01005-y.

77. Kappers IF, Verstappen FW, Luckerhoff LL, Bouwmeester HJ, Dicke M. Genetic variation in jasmonic acid- and spider mite-induced plant volatile emission of cucumber accessions and attraction of the predator Phytoseiulus persimilis. J Chem Ecol. 2010;36(5):500-12. https://doi.org/10.1 007/s10886-010-9782-6.

78. Schittko U, Preston CA, Baldwin IT. Eating the evidence? Manduca sexta larvae can not disrupt specific jasmonate induction in Nicotiana attenuata by rapid consumption. Planta. 2000;210(2):343-6. https://doi.org/10.1007/ PL00008143.

79. Baldwin IT, Staszakkozinski L, Davidson R. Up in smoke .1. smoke-derived germination cues for postfire annual, Nicotiana attenuata Torr ex Watson. J Chem Ecol. 1994;20(9):2345-71. https://doi.org/10.1007/BF02033207.

80. Glawe GA, Zavala JA, Kessler A, Van Dam NM, Baldwin IT. Ecological costs and benefits correlated with trypsin protease inhibitor production in Nicotiana attenuata. Ecology. 2003;84(1):79-90. https://doi.org/10.1890/00129658(2003)084[0079:ECABCW]2.0.CO;2

81. Krügel T, Lim M, Gase K, Halitschke R, Baldwin IT. Agrobacterium-mediated transformation of Nicotiana attenuata, a model ecological expression system. Chemoecology. 2002;12(4):177-83. https://doi.org/10.1007/PL00012666.

82. McGale E, Diezel C, Schuman MC, Baldwin IT. Cry1Ac production is costly for native plants attacked by non-Cry1Ac-targeted herbivores in the field. New Phytol. 2018;219(2):714-27. https://doi.org/10.1111/nph.15207.
83. Bubner B, Gase K, Berger B, Link D, Baldwin IT. Occurrence of tetraploidy in Nicotiana attenuata plants after Agrobacterium-mediated transformation is genotype specific but independent of polysomaty of explant tissue. Plant Cell Rep. 2006;25(7):668-75. https://doi.org/10.1007/s00299-005-0111-4.

84. Schuman MC, Palmer-Young EC, Schmidt A, Gershenzon J, Baldwin IT. Ectopic terpene synthase expression enhances sesquiterpene emission in Nicotiana attenuata without altering defense or development of transgenic plants or neighbors. Plant Physiol. 2014;166(2):779-U1010. https://doi.org/1 $0.1104 / p p .114 .247130$

85. Halitschke R, Schittko U, Pohnert G, Boland W, Baldwin IT. Molecular interactions between the specialist herbivore Manduca sexta (Lepidoptera Sphingidae) and its natural host Nicotiana attenuata. III. Fatty acid-amino acid conjugates in herbivore oral secretions are necessary and sufficient for herbivore-specific plant responses. Plant Physiol. 2001;125(2):711-7. https:// doi.org/10.1104/pp.125.2.711.

86. Xu SQ, Brockmoller T, Navarro-Quezada A, Kuhl H, Gase K, Ling ZH, et al. Wild tobacco genomes reveal the evolution of nicotine biosynthesis. P Natl Acad Sci USA. 2017;114(23):6133-8. https://doi.org/10.1073/pnas.1 700073114 .

\section{Publisher's Note}

Springer Nature remains neutral with regard to jurisdictional claims in published maps and institutional affiliations.

\section{Ready to submit your research? Choose BMC and benefit from:}

- fast, convenient online submission

- thorough peer review by experienced researchers in your field

- rapid publication on acceptance

- support for research data, including large and complex data types

- gold Open Access which fosters wider collaboration and increased citations

- maximum visibility for your research: over $100 \mathrm{M}$ website views per year

At BMC, research is always in progress.

Learn more biomedcentral.com/submissions 